\title{
Leadership Traits And Their Effects On Employees
}

\author{
Mohsin Shehzad \\ University of Management \& Technology \\ Abu Bakar Anjum \\ University of Management \& Technology \\ Muhammad Furqan \\ University of Management \& Technology
}

\begin{abstract}
The topic we selected is how leader, leadership qualities influence the employees performance. Leadership qualities were discussed at length in this research, what qualities are important and significant for leaders succeed in respect of employee performance in an organization. How leader of past and present differs? How this relation effects the organization because this relation can either make or break an organization. How leaders who own qualities are different from those who don't? This relation is of great importance because organizations success depends upon it. Organizations of today's world are going leaps and bounds in doing this research. It is also discussed that how leader behavior influence the employees. Also, our chosen topic is of broad nature so further research can also be done on this topic. The aim of our research was to see what is the relationship between these two variables is and how it affects an organization? Suggestions after concluding our result is also given on how in our opinion what leaders must possess and how employees, if leader possesses all the right ingredients, act in response?
\end{abstract}

Key Words: Employees, Performance, Leaders, Leadership, Qualities, Influence

\section{INTRODUCTION}

Leadership is considered to be a very broad concept. In today's world a lot of work is being conducting on leader and employee bond, how it affects the employee performance. There exists a considerable difference between a leader and a boss such as a boss will control his employees but it's a common known concept that leader motivates and encourage his employees. In general leader possesses qualities that he is always willing to learn, listen more to employees than talk, seek solutions, encourages and recognizes natural gifts of his employees, focuses on his team, takes responsibility and inspires performance. On the other hand a boss constitutes of qualities which are totally opposite to that of a leader. Dr. Robert Hogan argues that despite himself Steve Jobs was a successful charismatic and humble leader and Apple wasn't the same after passing of Steve Jobs also Hogan states that effective leader is a modest leader. A modest leader will listen to his subordinates, will admit his mistakes and be willing to change his course of action if he thinks his plan isn't working (Hogan, 2018).

Leaders of past had it easy because they were leading in a stable world where change wasn't so rapid. Nowadays leaders are dealing with a lot of factors because they are uncertain about future and their present is changing with every passing second. That's why on a global level leadership is being discussed and researched at length on improvement of leaders and their relation with their subordinates. From an employee's viewpoint today's leader numerous generations of workers who have different interests and moral values and from a customer's 
point of view a leader have to face great expectations. By putting this altogether there is a huge difference between leaders of past and today's leader.

Leadership is a combination of a number of qualities. Furnham maintains that leadership is the efficacy attained by means of achieving organizations objective and goals which indicates the qualities of a successful leader (Furnham, 2005). For an effective leadership, a leader must own traits of being a visionary, be courageous, be ethical, a good planner, humble towards others, must be focused, give priority to relationships over work, motivate others, be responsible and last but not the least he must be cooperative. Put together these are some important qualities which makes a leader productive, successful and effective. On the other hand if a leader lacks these qualities it will be difficult for him to lead and followers will hesitate and avoid him altogether.

Above mentioned qualities are of great importance and one cannot be a victorious leader if he doesn't possesses these traits. Surely there exists a significant difference between leaders who owns these qualities and leaders who don't.

It's a predicament in today's world that what influence does leadership traits have on employees and their performance

\section{LITERATURE REVIEW}

Under discussion are the qualities a leader possesses and influence of these qualities on the performance of his followers (employees). Leaders who own these qualities mentioned above and leaders who don't own these qualities are not same. It is a common concept that leadership is the combination of different characteristics, qualities and actions and these qualities are used when interacting with his workforce. (Mitonga-Monga, 2012). As we know that in today's world Leadership is considered to be a very broad topic. Every individual has its own personality, thinking and behavior so a leader have to consider all the aspects while dealing with every individual. According to (Harris, 2007) leadership can be seen as a relationship used by an individual for making people work together to attain a common goal.

Performance can be measured by evaluating that at what degree an organization has achieved its desired objectives. A leader plays a key role in relation to the performance of employees whether they are individual, in teams or in groups. Every individual's attitude towards leader a behavior is different because there is a direct relationship between a leader's behavior and an employee's performance. Mostly It depends on a leader that how he handles every employee under his leadership. In the view of (NA, 1982) "he claims that without followers there will be no leaders". More than half a century of research concludes that a leader can boost the performance of an individual, team, and group by using a combination of particular tasks and relations building according to the situation. To understand the impact of leadership on employee performance, it is of paramount nature that leadership play a significant role in developing the performance of individuals in an organization. (Obiwuru, 2011).

Analyzing employee performance is a complex scenario because every individual deals with leader behavior in his own way. In any organization performance is measured by comparing the results of employees with that of set objectives and goals by a leader. According to (Klein, 2013)“a leader behavior affects the culture of an organization which in turn influences the employee performance". It is clear that leader behavior significantly impacts the organizational on more than one level and one can even say that an organizations success may also depends on a leader behavior. A leader behavior can be judged by the qualities he owns. 
There is no doubt that a leader behavior is considered important for employees but we also have to mention that leader's behavior to some extent depends on the behavior of his subordinates. It is on the part of employees that if their leader's behavior is positive in return they must work hard and deliver their full. In one way or another employee's behavior depends on how satisfied he is with his job and organization and last but not the least his leader. If an employee is satisfied his engagement with his work will be high, he will perform his tasks energetically and with complete concentration. Thus, employees who are satisfied, they are engaged in their work have an energetic, enjoyable, and effective connection with their work. (Kahn, Psychological conditions of personal engagement and disengagement at work, 1990). It is reasonable to say that organizations whose employees are more engaged with their work are more successful

Than those whose employees are not engaged. It's logical that organizations wish to increase employee engagement, given that engaged employees are willing to make use of their full selves in their work roles in a positive way. (Kahn, Psychological conditions of personal engagement and disengagement at work, 1990).

Significance of leader and employee relation cannot be denied. Its importance can be seen by the fact that a ton of research is being conducted on this topic. Organizations are investing on a large scale on how to develop successful, fruitful and long term leader-employee relationship which benefits the organization. Because the relation between leader and employee can either make or break an organization that's why this matter has a significant importance.

Our topic includes how a leader and the qualities he possesses and a leader's behavior affects employees and their performance in an organization. What kind of leaders proves to be effective? How employees perceive leaders with positive qualities and what happens when the situation is vice versa? Does this relation affect an organization and if it does, in what way?

\section{QUESTION}

Focus of our research is based on these following questions:

- What is a leader?

- Qualities of a leader?

- Impact of both on the performance of employees in an organization?

\section{METHODOLOGY}

After analyzing almost every aspect a self-design questionnaire developed that focuses and attempt to evaluate the impact of leader, leadership qualities on employee's performance. The main focus of this research is how employees and their work is affected depending on their leader's qualities. The data is taken from the employees which of private sectors about their leaders who are at managerial level and our sample size is 100 as we have done convenient sampling. Every respondent was asked to provide their honest opinion regarding our research topic. After collecting our required data, SPSS was used for running the collected result and see what will be the outcome.

\section{RESULTS}

The age table represents the different age level of respondents with different age groups, which attempted the questionnaire. There are $4 \%$ respondents of age group between 15-20 years out of 100 respondents, $47 \%$ are between $20-25$ years, and $42 \%$ falls in $25-30$ and $7 \%$ in 30-35years of age group. 


\begin{tabular}{|c|c|c|c|c|c|}
\hline \multicolumn{6}{|c|}{ Age } \\
\hline & & Frequency & Percent & Valid Percent & $\begin{array}{c}\text { Cumulative } \\
\text { Percent }\end{array}$ \\
\hline \multirow[t]{5}{*}{ Valid } & $15-20$ & 4 & 4.0 & 4.0 & 4.0 \\
\hline & $20-25$ & 47 & 47.0 & 47.0 & 51.0 \\
\hline & $25-30$ & 42 & 42.0 & 42.0 & 93.0 \\
\hline & $30-35$ & 7 & 7.0 & 7.0 & 100.0 \\
\hline & Total & 100 & 100.0 & 100.0 & \\
\hline
\end{tabular}

The qualification table represents the different level of respondents which attempted the questionnaire. There are $4 \%$ related to metric, 38\% to intermediate, $54 \%$ to bachelor's and at master's level there are $4 \%$.

\begin{tabular}{|ll|c|c|c|c|}
\hline \multicolumn{1}{|c|}{ Qualification } \\
\cline { 3 - 6 } & Frequency & Percent & Valid Percent & $\begin{array}{c}\text { Cumulative } \\
\text { Percent }\end{array}$ \\
\hline Valid & Metric & 4 & 4.0 & 4.0 & 4.0 \\
& Intermediate & 38 & 38.0 & 38.0 & 42.0 \\
& Bachelor & 54 & 54.0 & 54.0 & 96.0 \\
& Master & 4 & 4.0 & 4.0 & 100.0 \\
& Total & 100 & 100.0 & 100.0 & \\
\hline
\end{tabular}

The gender table represents the rate of respondents participated in our questionnaire. There are 100 respondents and they have a significant contribution in this research. The table shows that there are $61 \%$ related to males and $39 \%$ related to females.

\begin{tabular}{|ll|c|c|c|c|}
\hline \multicolumn{5}{|c|}{ Gender } \\
\hline \multirow{2}{*}{ Valid } & Male & 61 & 61.0 & 61.0 & $\begin{array}{c}\text { Cumulative } \\
\text { Percent }\end{array}$ \\
& Female & 39 & 39.0 & 39.0 & 61.0 \\
& Total & 100 & 100.0 & 100.0 & 100.0 \\
\hline
\end{tabular}

\section{CONCLUSION}

The topic of our research was to determine that what describes the leader, leadership qualities and how they impact employee performance. In this reference our independent variable is leader and leadership qualities and dependent was employee performance. We wanted to see is that is there a relation between these two variables and whether there is a direct or indirect relation between these two.

From our data collected we have concluded that there exists a direct relationship between these two variables. One will affect the other either in a positive or negative way. Our collected data show that these two variables are directly related to each other.

Our results showed that in respect of leader and leadership qualities, leaders who possess the above mentioned qualities and remain humble towards their employees are more successful than those who are opposite. Our selected sector showed that leaders don't own the qualities and negatively affects the employees and their performance.

In respect of employee's performance our results showed that employee performance is greatly affected by the leader qualities and behavior. Our results showed that employees are 
not satisfied with their leaders and are not motivated. In the end our results showed that there is a negative relationship between leader, leadership traits and employee performance.

\section{FURTHER RESEARCH}

Organizations, who want success in the world market and desire continuous growth spending tons on how to improve themselves and deliver the best of them. One of the paramount nature of factor is to consider in this aspect is how leader behavior is linked with employee performance. Globally, organizations which are successful in this regard are creating special departments and conducting seminars, surveys and proper workshops in making this relation perfect. If in an organization employees are satisfied as in they have fruitful leader-employee relation, everything else related to work becomes unproblematic.

Topic of our research is of very broad nature and a lot of research has being conducted in past and is still being researched. This topic includes lots of elements, factors and angles, some main factors are leader, behavior, employees, performance and organization. Besides these, there also exist numerous factors to be included in this area.

\section{SUGGESTION}

In my opinion and to best of my knowledge we would humbly suggest that as leader and employee relationship is of great importance in our society so leaders on their part and employees on their parts must try at their best to make this relation more effective and efficiently. Leaders are considered to be a role model in the society and if they are honest, humble, co-operative, supportive, motivate others, inspire others, good at communication with others, consider himself accountable for his actions, a man of his word and always fulfills his commitments. These are along with many other qualities makes a leader irreplaceable and it can be seen that employees who works under the leadership of leaders like this, they are more productive and efficient and enjoy their work. So leaders of today must try to focus and adopt more and more to acquire these kind of qualities for the greater and collective good. As it can be seen around the world in respect of organizations and as well as nations that leaders who possesses these qualities are more triumphant than those who don't i.e. Apple-Steve Jobs and Nelson Mandela.

There are two sides of everything, this being said, employee's must also not be completely dependent on their leaders, if their leader is all those things mentioned above they must on their part put maximum effort in whatever work they do. They must be at their best and they must prove themselves worthy, they must try not to complain, if there is a conflict, they must try to mitigate it, they must try to be more and more competent.

In the end if a leader occupies all those qualities, employees also must not create any problematic situations, avoid conflicts and be at their best in whatever they do.

\section{References:}

Furnham, A. (2005). Managers as change agents. Journal of Change Management, 3(1), 21-29.

Harris, A. e. (2007). Distributed leadershio and organizational change:Reviewing the evidence. Journal of educational change, 8(4), pp. 337-347.

Hogan, D. R. (2018, july 18). forbes. Retrieved from forbes.com: www.forbes.com

Kahn, W. A. (1990). Psychological conditions of personal engagement and disengagement at work. Academy of Management Journal, Vol. 33 No. 4, 692-724.

Kahn, W. A. (1990). Psychological conditions of personal engagement and disengagement at work. Academy of Management Journal, Vol. 33 No. 4, 692-724. 
Klein, A. S. (2013). The impact of leadership styles on organizational culture and firm effectiveness:An empirical study. Journal of Management \& organization, 19(3), pp. 241-254.

Mitonga-Monga, J. \&. (2012). Perceived leadership style and employee. African Journal of Business, 6(15).

NA, E. (1982). Psychological Approach to Leadership in Nigerian Organization., (pp. Annual conference of the Nigerian psychological society,). Ibadan.

Obiwuru, T. C. (2011). Effects of leadership style on organization performance. Australian Journal of Business and Management Research, 100-111. 